\title{
Endocardial Heart Tube
}

National Cancer Institute

\section{Source}

National Cancer Institute. Endocardial Heart Tube. NCI Thesaurus. Code C34161.

The paired, longitudinal endothelial-lined channels formed from mesenchyme in the cardiogenic area of the embryo during the third week of development, which will fuse into a single heart tube forming the primitive heart. 